DIW BERLIN

Discussion

Papers

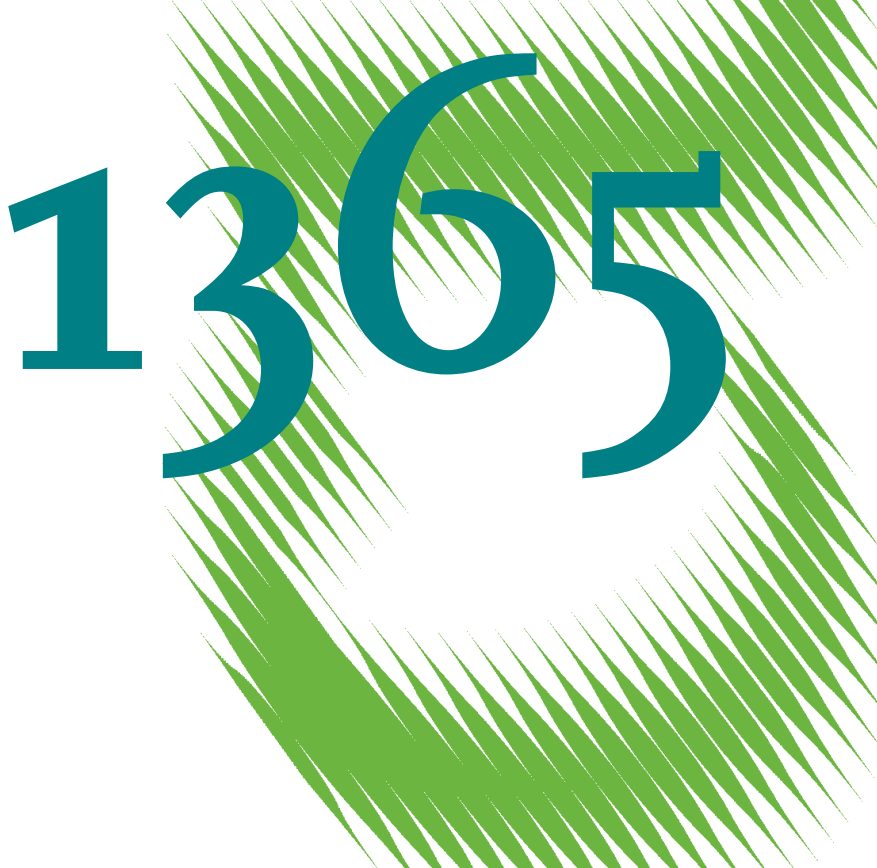

On the Relationship between Public and Private Investment in the Euro Area 
Opinions expressed in this paper are those of the author(s) and do not necessarily reflect views of the institute.

IMPRESSUM

(C) DIW Berlin, 2014

DIW Berlin

German Institute for Economic Research

Mohrenstr. 58

10117 Berlin

Tel. $+49(30) 89789-0$

Fax +49 (30) $89789-200$

http://www.diw.de

ISSN print edition $1433-0210$

ISSN electronic edition 1619-4535

Papers can be downloaded free of charge from the DIW Berlin website:

http://www.diw.de/discussionpapers

Discussion Papers of DIW Berlin are indexed in RePEc and SSRN:

http://ideas.repec.org/s/diw/diwwpp.html

http://www.ssrn.com/link/DIW-Berlin-German-Inst-Econ-Res.html 


\title{
On the relationship between public and private investment in the euro area
}

\author{
Christian Dreger, Hans-Eggert Reimers $^{1}$
}

\begin{abstract}
This paper explores the long run relationship between public and private investment in the euro area in terms of capital stocks and gross investment flows. Panel techniques accounting for international spillovers are employed. While private and public capital stocks are cointegrated, the evidence is quite fragile for public and private investment flows. They enter a long run relationship only after fundamental drivers of private investment, such as demand and financing costs are included. According to the impulse response analysis, private investment reacts to shocks in public investment both in terms of stock and flow variables. In contrast, public investment is rather exogenous. Therefore, the lack of public investment might have restricted private investment and GDP growth in the euro area. The results have strong implications for the future direction of fiscal austerity programs to combat the euro area debt crisis.
\end{abstract}

JEL: C23, E22, E62

Keywords: Public and private investment, fiscal austerity, panel VAR

\footnotetext{
${ }^{1}$ Dreger (corresponding author): DIW Berlin, Mohrenstr. 58, D-10117 Berlin, email: cdreger@diw.de, Phone/Fax: +49-30-89789529/102. Reimers: Hochschule Wismar, Postfach 1210, D-23952 Wismar, email: hans-eggert.reimers@hs-wismar.de, Phone/Fax: +49-3841 753601/131.
} 
While fiscal austerity is beneficial for GDP growth in the long run, the impacts in the short and medium run are often negative, as witnessed by the public debt crisis in the euro area. The consolidation of public finances through a reduction of fiscal expenditures and an increase in taxes have caused deep recessions in many countries (see for example Auerbach and Gorodnichenko, 2012). To foster economic growth in times of debt is a main challenge for policymakers.

This study investigates the relation between public and private investment for the euro area. From a theoretical perspective, there is evidence for effects in both directions. On the one hand, if public and private sectors compete for the same resources, the costs for private investment can increase. Public investment needs to be financed, which may imply a higher tax burden or higher demand of governments for funds in capital markets, therefore causing interest rates to rise. Even from a Keynesian perspective, crowding-out effects of private investment are expected. They will be reinforced in times of a crisis, since higher government debt can raise country-specific risk and interest rates. On the other hand, public investment may create more favourable conditions for private investment, for example, by providing better infrastructure. The existence of facilities can increase productivity of private investment, which might take advantage of improved business conditions. For example, government investments in energy, telecommunications or other network industries may have stimulated private investment activities (see Dethier and Moore, 2012).

Due to the opposite effects, the net impact of public on private investment is not determined on a priori grounds. Consequently, previous studies have delivered inconclusive results with respect to crowding-out or crowding-in. As the net impact comprises both static and dynamic reactions, any analysis should distinguish between the short and long run of the direction. While crowding-out is mainly a short-run phenomenon related to restrictions on available resources, crowding-in is more long-lasting and traced to higher productivity of private capital. Thus, if there are crowding-in effects, they may be eventually more relevant in terms of the stock variables.

In his seminal contribution, Aschauer (1989) emphasized the possibility that public investment may induce private investment. In general higher public capital accumulation tends to raise the overall investment rate above the level chosen by rational agents implying an ex ante crowding out of private investment. However, crowding-in effects will finally dominate. An expansion of 
public capital is expected to increase the rate of return to private capital, thereby leading to higher private capital accumulation and GDP growth. Hence, active fiscal policies could stimulate private investment through productivity gains stemming from public capital. The results suggest that private investment will raise permanently by more than one to one for every unit of non-defense public capital. Evidence is based on a static production function specified in levels for the US. Subsequent research based on regional production functions, disaggregated public capital or industries arrived at similar conclusions, particularly for roads and highway capital. Argimón, González-Páramo and Roldán (1997) reported significant crowding-in effects of public on private investment for OECD countries through the positive impact of infrastructure on productivity. In contrast, government consumption will crowd out private investment. Thus, debt reductions engineered through cuts in public investment can severely impinge on private investment and growth prospects.

The positive assessment of public investment expenditures lacks robustness, as the empirical model plays a crucial role. The integration properties of the variables can heavily influence the results, but have been largely ignored in the aforementioned studies. If production functions are estimated with differenced data or if pooled regressions are carried out with fixed effects, crowding-in effects seem to diminish. Instead, negative marginal products of public capital can be are detected. See Perotti (2007) for a recent survey. Using country specific VARs in first differences, Afonso und Aubyn (2009) found crowding-in effects of public investment for some countries, but crowding out effects for others. The reversed direction appears to be even more general. In fact, an acceleration of private investment raises GDP and revenues to spend for public investment. Based on a panel VAR in first differences Marattin and Salotti (2011) concluded that shocks in fiscal spending exert positive effects on private consumption and investment in the euro area.

This paper differs from previous studies in several respects. First, we provide evidence on the long-run relationship between private and public investment by examining capital stocks as well as gross investment flows. Both alternatives are considered to assess the robustness of the results. While stocks are I(2), flows are I(1) variables. Second, the relationship is investigated in a panel VAR framework, where the euro area member states constitute the cross section. The panel dimension avoids the shortage of degrees of freedom often embedded in a time series VAR. In addition, the model can capture international spillovers, while allowing for unobserved heterogeneity caused by different institutional settings. Finally, short and long run effects can be distinguished, as an error correction mechanism is involved. While capital stocks 
are cointegrated, the evidence is quite fragile for investment flows. They enter a long run relationship only after fundamental drivers of private investment, such as demand and financing costs are included. According to the impulse response analysis, private investment reacts to shocks in public investment and to capital adjustment towards the stock equilibrium. In contrast, public investment is found to be exogeneous. Thus, the lack of public investment might have restricted private investment and GDP growth in the euro area.

The results have strong implications for the future direction of fiscal austerity programs to combat the euro area debt crisis. In fact, economic growth in the euro area could benefit from further fiscal reforms. For example, the exclusion of national co-funding of EU-supported investments from the fiscal indicators considered in the Stability and Growth Pact could be a sensible strategy (Barbiero and Darvas, 2014). The recently introduced European Semester designed to better monitor fiscal planning at the individual country level should encourage higher investment activities by member states, in particular of those with healthy public finances and low public investment rates.

The rest of the paper is structured as follows. The next section (Section 2) motivates a long-run equilibrium between private and public investment. Afterwards, Section 3 discusses the econometric methodology. Section 4 holds the empirical results. Finally, Section 5 concludes with some policy recommendations.

\section{$2 \quad$ Long run equilibrium between private and public capital}

To address the possible crowding-in effect it is necessary to examine the relationship between private and public capital. Assuming that the Cobb Douglas production function with constant returns to scale, output $Y$ is related to technical progress $A$, labour $L$, private capital $K$ and public capital $G$, i.e.

$$
\text { (1) } \quad Y_{t}=A_{t} L_{t}^{\alpha} K_{t}^{\beta} G_{t}^{\gamma}
$$

The parameters $\alpha, b$ and $\gamma$ denote production elasticities. While the marginal product of private capital is $6 Y / K$, the marginal product of public capital is $Y Y / G$. In equilibrium, the marginal products should be equal to the respective real interest rates

(2) $\beta Y_{t} / K_{t}=r p_{t}, \gamma Y_{t} / G_{t}=r g_{t}$ 
in the private $(r p)$ and public sector $(r g)$. As the interest rates are subject to arbitrage, they will eventually move in parallel, despite possible differences related to risk premia (Hatano, 2010). If the interest rates maintain a constant ratio, $r p=\lambda r g$, one can obtain

(3) $\quad K_{t}=\frac{\beta}{\lambda \gamma} G_{t}$

implying that the capital stocks are cointegrated. If the marginal products are equalized, the cointegration parameter will simply reflect the ratio of the production elasticities. Equation (3) will be tested in terms for the capital stocks. If the stocks are cointegrated, they should expand at the same rate, implying that public and private investment are cointegrated as well. Therefore, we will also investigate the existence of a long run equilibrium between public and private investment flows ${ }^{2}$. Note that any direction of causality is not assumed in the argument. However, if public investment is exogenous, private investment will react to deviations from the long run, implying that deviations from the cointegrating relationship can be seen as a driver for private investment.

\section{Econometric approach}

Panel VAR models

Panel VARs are designed to capture both static and dynamic interdependencies across countries or regions using some set of restrictions, treat the linkages across units, and can account for cross sectional heterogeneities (Canova and Cicarelli, 2013). They extend the standard VAR framework to panel data by adding a cross section dimension. The reduced form of the model can be stated as

(4)

$$
y_{i t}=v_{0 i}+A_{i}(L) Y_{t-1}+u_{i t} \quad, \quad i=1, \ldots, N \quad, \quad t=1, \ldots, T
$$

$Y_{t}=\left(y_{1 t}{ }^{\prime}, y_{2 t}{ }^{\prime}, \ldots, y_{N t}{ }^{\prime}\right)^{\prime}$.

\footnotetext{
${ }^{2}$ Equation (3) implies cointegration between net investment flows, i.e. gross investment less depreciation. To be consistent with other studies, this property is explored by employing gross investment flows. The difference is not crucial for the analysis. From an empirical perspective, capital stocks are $I(2)$ variables. As net investment flows are cumulated to obtain the stocks, they match the integration properties of gross investment flows, which are $I(1)$.
} 
The $m$ endogenous variables constitute the vector $y ; Y$ is the stacked version of $y$ comprising the variables for all countries, $v_{0}$ is a vector of intercepts that could also depend on time, $A_{\mathrm{i}}(L)$ is a polynomial in the lag operator $L$ for the coefficients of the lagged regressors and $u$ is a vector of random disturbances. The indices $i$ and $t$ refer to the country and time period, respectively. Lags of all variables of all units are allowed to enter the equations for each unit, thereby including dynamic interdependencies. Static interdependencies could arise, as the errors are correlated across the units. Cross sectional heterogeneity is embedded, since all parameters might be unit specific.

The panel VAR in its unrestricted form cannot be estimated due to the lack of degrees of freedom. However, the panel structure suggests possible restrictions (Lütkepohl, 2014). In fact, if dynamic interdependencies between panel members can be neglected and if the coefficients are approximately the same for all countries except of the intercepts, the panel VAR might be rewritten as

$$
y_{i t}=v_{0 i}+A(L) y_{i t-1}+u_{i t} \quad, \quad i=1, \ldots, N \quad, \quad t=1, \ldots, T
$$

In the restricted version, interdependencies can still occur through the correlation of residuals across units. While the advantage of the panel setup is an increase in the number of observations implying more efficient estimates especially in case of low frequency data, the disadvantage is the need to impose homogeneity restrictions. Therefore, the selection of the appropriate model depends on the question under study. In fact, potential heterogeneities might be limited in this study, as the euro area countries share many similarities and are part of an integrated economic area. Expansionary fiscal policies do not lead to strong cross country spillovers, as shown by the recent financial crisis. As a response to the economic downturn, fiscal stimulus packages were launched, but in a rather uncoordinated way across member states. At the same time, persistent unobserved heterogeneities can be preserved due to the presence of unit specific intercepts, i.e. fixed effects. Hence, the restricted model (5) can serve as a point of departure.

The standard approach to estimate the parameters of the model is pooled regression combined with fixed effects. Since the fixed effects are correlated with the regressors because of the lags of the variables, the mean-differencing procedure often used to eliminate the intercepts will inevitably lead to biased estimates (Arellano and Bond, 1991). To overcome this problem, forward-mean differencing via the Helmert transformation is involved, see Arellano 
and Bover (1995). This procedure preserves the orthogonality between the transformed variables and lagged regressors. The latter are taken as instruments to estimate the coefficients by the system GMM, as proposed by Holtz-Eakin, Newey and Rosen (1988) and Love and Zicchino (2006). Once the parameters have been estimated, the reactions of one variable to the innovations of another variable can be revealed from impulse response analysis and variance decomposition. While impulse response functions describe the reactions of a variable over time to a shock in other variables of the system, variance decompositions measure the contributions of each shock to the forecast error variance of each variable for a particular forecasting horizon. For an appropriate interpretation, the shocks need to be identified, i.e. an orthogonal transformation of errors is involved. This is achieved by the lower triangular Cholesky decomposition. It implies a causal ordering of the series, depending on their contemporaneous impact on other variables. Since dynamic interdependencies across units are excluded in the restricted model, the ordering of countries does not affect the results.

\section{Panel integration and cointegration}

The panel VAR can be specified in terms of the level variables, irrespectively whether they are stationary or not. If they include stochastic trends, cointegration relationships are implicitly embedded, as in the time series case (Sims, Stock and Watson, 1990). In this application, the long run is explicitly extracted to improve the economic interpretation of the results. In order to check the unit root properties of the variables, panel integration tests allowing for cross section spillovers are applied. According to the Pesaran (2007) CADF routine, the standard ADF equation

$$
\Delta y_{i t}=\alpha_{i}+\delta_{i} y_{i t-1}+\lambda_{i} \bar{y}_{t-1}+\theta_{i} \Delta \bar{y}_{t-1}+u_{i t} \quad, \quad \bar{y}_{t}=N^{-1} \sum_{i=1}^{N} y_{i t}
$$

is extended with cross section averages of lagged levels and first differences of the series of interest. The regression is carried out for each panel member and can be extended by lagged values of the endogenous variable to account for autocorrelation in the residuals. Testing for the null of a unit root is based on the $t$-ratio of the first order autoregressive parameter $(\delta)$. To construct the panel statistic, the $t$-values are pooled across individuals. A standardized version is asymptotically distributed as standard normal under the joint null hypothesis of nonstation- 
arity for all individuals. If the null is rejected, the series is stationary at least for one panel member.

The cointegration properties are investigated by the panel and group mean statistics suggested by Westerlund (2007). They do not rely on a potential inappropriate common factor restriction such as the tests based on the residuals obtained from static relationships; see Kremers, Ericsson and Dolado (1992). The null hypothesis of no cointegration between $y$ and $x$ is evaluated by testing whether the feedback parameter $(\gamma)$ in a conditional panel errorcorrection model

$$
\Delta y_{i t}=\alpha_{i}+\gamma_{i} y_{i t-1}+\lambda x_{i t-1}+\sum_{j=1}^{p} \theta_{i} \Delta y_{i t-j}+\sum_{j=-q}^{p} \beta_{i} \Delta x_{i t-j}+u_{i t}
$$

is equal to zero. The error-correction models are estimated separately for the panel members and the statistics are pooled along different principles. If the null is rejected, cointegration is assumed to hold for all units in case of the panel statistics, and at least for one individual in the group statistics. All tests are asymptotically distributed as standard normal and can account for individual short-run dynamics, trends and slopes. Leads and lags of differenced variables can be included due to information criteria. Since the cross sections are not independent, critical values are obtained by bootstrap methods.

Note that panel cointegration tests do not reveal the long run parameters. Their aim is to identify reliable empirical models of integrated variables to avoid spurious regressions. Therefore, after testing for cointegration, the long run is estimated via pooled regression with fixed effects and contemporaneous correlation in the residuals. This approach is valid, if cointegration has been confirmed in advance, i.e. if spurious regressions can be excluded. While the intercept, short run coefficients and error variances can differ across the panel members, the long run coefficients are restricted to be identical over the cross section.

\section{$4 \quad$ Data issues and empirical results}

Evidence on the link between public and private investment is based on annual data for the 1991-2012 period. The panel is based on 12 euro area member states, comprising Germany, France, Italy, Spain, Portugal, Greece, Ireland, Austria, Finland, Netherlands, Belgium and Luxembourg. Countries that joined the monetary union in recent years are excluded due to the 
lack of data. All series are taken from the AMECO database which is provided by the European Commission.

While net investment flows are available at the sectoral level, capital stock data refer to the entire economy. To construct public and private capital stocks, net investment flows are cumulated. Starting values result from a decomposition of total stock in an initial period (1990). In fact, the share of public capital is assumed to be equal to the ratio of cumulated net public to cumulated net overall investment, where the 1980s are taken as the reference period. To reveal insights on cointegration between flows, gross capital formation in the public and private sector are selected. All variables are divided by the appropriate deflator $(2005=100)$ to obtain series in real terms.

Fundamental determinants of investment are considered to assess the robustness of the results. Real GDP and real interest rates are included as a proxy for overall demand and financing costs to invest, respectively. To obtain real GDP, the nominal series is deflated by the GDP deflator $(2005=100)$. Real interest rates are defined in an ex post manner as the difference between the long term nominal interest rate and inflation, i.e. the annual change in the GDP deflator. Furthermore, Brautzsch and Dreger (1999) noted that the government debt ratio can potentially explain private investment. An increase in the debt ratio worsens the financial conditions via higher real interest rates. It can also restrict future demand, as investors might fear stronger efforts towards fiscal consolidation in later periods. Mehrotra and Välilä (2005) found a negative effect on public investment of high public debt in a panel cointegration model for EU member states. In line with the Maastricht criterion, the debt ratio is defined as the ratio between gross government debt and GDP. All variables are measured in logs, except of real interest rates.

\section{-Table 1 about here-}

The first step refers to the unit root properties of the variables involved. According to the results in the upper part of Table 1, capital stocks include two unit roots. This is in contrast to results of Calderón, Moral-Benito and Servén (2014), who present evidence that the capital stock is I(1) in panel of 88 countries including rich and developing countries. The other variables are nonstationary in their levels and stationary in the first differences. As real interest 
rates and government debt ratios cannot move without bounds, the outcome may be doubted for these variables from a theoretical view. However, they appear to be integrated in a statistical sense and should be treated as such in the empirical analysis. The lower part of Table 1 holds the cointegration results. The long run property is tested for different subsets of variables to obtain reliable evidence. Gross public and private investment flows are not cointegrated in the euro area. However, they can enter an extended long run relation, if fundamental drivers of investment are taken into account. However, the latter determinants, like overall demand in the economy, real interest rates or public debt ratios appear to be far more important. The evidence in favor of cointegration is stronger in a model comprising real interest rates instead of public debt ratios. To summarize, the link between public and private investment is not well supported in the flow model. In contrast to the evidence based on flows, the capital stocks appear to be cointegrated. Therefore, there is a long run link between public and private investment, but it should be expressed in terms of stocks. Note that the deviations from the stock equilibrium do not need to be stationary. In principle, they can be also I(1), due to their I(2) ingredients.

If cointegration is detected between certain sets of variables, the long run parameters can be estimated by pooled regression techniques. As it is shown in Table 2, the coefficients of the relationships are well signed. Higher demand and lower financing costs will stimulate private investment. Furthermore, a one percent increase in public investment will trigger a 0.2 percent increase of private investment flows on average in the long run. An expansion of the public capital stock by one percent will lead to a less than proportional rise in private capital. According to equation (3), the elasticity of 0.8 implies that the production elasticity of private capital is slightly less than the product of the production elasticity of public capital times a risk premium for government bonds.

-Table 2 about here-

Insights into the direction of the causality are obtained from a restricted panel VAR, see equation (5). As it is specified in terms of the level variables, the cointegrating relationships are implicitly embedded. The identification scheme is based on a lower triangular Cholesky decomposition with the ordering of variables according to 
Stock model: (CS_PUB, CS_PRI).

A variable coming earlier in the ordering affects the next ones both contemporaneously and with a lag, while a variable coming later has only lagged effects on the preceding ones. In the flow model, gross public investment $(P U B)$ is the most exogenous variable, since it is a policy instrument and can be decided independently. However, it will affect real interest rates $(R)$, in particular if the expenditures are financed by new debt. Both public investment and interest rates affect overall demand $(Y)$. Depending on these conditions, the agents decide on the level of private investment $(P R I)$. In the stock model, public capital comes first, as it an increase the productivity of private investment. As the identifying assumptions might be critical, especially with respect to the annual data frequency, different identification schemes have been also chosen, but did not affect the results in a substantial way. The results are exhibited for short and medium horizons in Table $3 .^{3}$

The flow specification does not indicate a huge role of public investment. In fact, the responses of private investment to shocks in public investment are insignificant. As a consequence, unexpected variations in public investment account only for 3 percent in the forecast error variance in gross private investment flows. The insignificant responses may be result from the heterogeneity of the countries documented by Afonso and Aubyn (2009), who find crowding out effects in Belgium, Ireland, the United Kingdom and the Netherlands and crowding in effects in Austria, Germany, Denmark, Finland, Greece, Spain and Sweden. The reversed relationship appears to be more important. Shocks in private investment trigger significant responses in public investment and are able to explain about 30 percent of the respective forecast error variance. Moreover, the own responses of the investment variables dominate the impulse response results and variance decomposition due to the high fluctuations of these series. Therefore, the positive effects of public investment in infrastructure may be only realized with considerable lags.

In contrast to the flow model, the role of public investment is more important if the stocks are considered. The adjustment of private capital to shocks in public capital appears to be signifi-

\footnotetext{
${ }^{3}$ It is worth mentioning that 5 years imply 20 quarters, a value which is used for example by Afonso and Aubyn (2009). The panel VAR model has been estimated using the Stata program provided by Love and Zicchino (2006).
} 
cant and the latter are able to account for 50 percent of the variance of the former. The impulse responses also reveal a minor impact running in the opposite direction. As public capital will decline after a positive shock in private capital, it may be traced to some anticyclical behavior of the government. Overall, the stock model reveals a crucial role of public capital for private investment behavior that would be largely underestimated if the analysis is focused on flows.

-Table 3 about here-

\section{Conclusions}

This paper explores the long run relationship between public and private investment in the euro area in terms of capital stocks and gross investment flows. Panel techniques accounting for international spillovers are employed. While private and public capital stocks are cointegrated, the evidence is quite fragile for public and private investment flows. They enter a long run relationship only after fundamental drivers of private investment, such as demand and financing costs are included. According to the impulse response analysis, private investment reacts to shocks in public investment both in terms of flow but more pronounced of stock variables. In contrast, public investment appears to be exogenous, which stresses the public investment variable as a policy variable.

Thus, the lack of public capital as a result of weak public investment might have restricted private investment and GDP growth in the euro area. The results have strong implications for the future direction of fiscal austerity programs to combat the euro area debt crisis. In particular, economic growth in the euro area could benefit from further fiscal reforms. A modified framework should encourage higher investment by the member states, in particular of those with healthy public finances and low public investment rates. This would be part of an integrated approach to overcome the crisis and to achieve a path of stronger GDP growth in the future. 


\section{References}

Afonso A, Aubyn M (2009): Macroeconomic rates of return of public and private investment: Crowding-in and crowding-out effects, Manchester School 77, 21-39.

Argimón I, González-Páramo JM, Roldán JM (1997): Evidence of public spending crowding-out from a panel of OECD Countries, Applied Economics 29, 1001-1010.

Arellano M, Bond S (1991): Some tests of specification for panel data: Monte Carlo evidence and an application to employment equations, Review of Economic Studies 58, 277-297.

Arellano M, Bover O (1995): Another look at the instrumental variable estimation of error component models, Journal of Econometrics 68, 29-51.

Auerbach A, Gorodnichenko Y (2012): Measuring the output responses to fiscal policy, American Economic Journal: Economic Policy 4, 1-27.

Aschauer DA (1989): Does public capital crowd out private capital? Journal of Monetary Economics 24, 171-188.

Barbiero F, Darvas Z (2014): In sickness and health: Protecting and supporting public investment in Europe, Bruegel Policy Contribution 2014/02.

Calderón C, Moral-Benito E, Servén L (2014): Is infrastructure capital productive? A dynamic heterogeneous approach, Journal of Applied Econometrics, DOI: 10.1002/jae.2373.

Dethier JJ, Moore A (2012): Infrastructure in developing countries: An overview of some economic issues, ZEF-Discussion Papers on Development Policy 165, University of Bonn.

Dreger C, Brautzsch H-U (1999): Die Entwicklung der Unternehmensinvestitionen in Deutschland (Firm investment behaviour in the German economy), Journal of Economics and Statistics 219, 284-297.

Canova F, Ciccarelli M (2013): Panel vector autoregressive models: A survey, ECB Working Paper 1507.

Hatano T (2010): Crowding-in effect of public investment on private investment, Japan Public Policy Review 6, 105-119.

Holtz-Eakin D, Newey W, Rosen HS (1988): Estimating vector autoregressions with panel data, Econometrica 56, 1371-1395. 
Kremers JM, Ericsson NR, Dolado JJ (1992): The power of cointegration tests, Oxford Bulletin of Economics and Statistics 54, 325-48.

Love I, Zicchino L (2006): Financial development and dynamic Investment behavior: Evidence from panel VAR, Quarterly Review of Economics and Finance 46, 190-210.

Lütkepohl H (2014): Structural vector autoregressive analysis in a data rich environment, DIW Discussion Paper 1351.

Marattin L, Sallotti S (2011): On the usefulness of government spending in the euro area, Journal of Socio-Economics 40, 780-795.

Mehrotra A, Välilä T (2005): Evolution and determinants of public investment in Europe, Economic and Financial Reports 2005/1, European Investment Bank.

Perotti R (2007): In search of the transmission mechanism of fiscal policy, NBER Working Paper 13143.

Persyn D, Westerlund J (2008): Error correction based cointegration tests for panel data, Stata Journal 8, 232-241.

Pesaran MH (2007): A simple panel unit root test in the presence of cross section dependence, Journal of Applied Econometrics 22, 265-312.

Sims CA, Stock, JH, Watson MW (1990): Inference in linear time series models with some unit roots, Econometrica 58, 113-144.

Westerlund J (2007): Testing for error correction in panel data, Oxford Bulletin of Economics and Statistics 69, 709-748. 
Table 1: Integration and cointegration properties of the variables involved

Tests for integration according to Pesaran (2007)

\begin{tabular}{|c|c|c|c|}
\hline & Levels & First differences & Decision \\
\hline$C S \_P R I$ & $\begin{array}{c}0.649 \\
(0.742)\end{array}$ & $\begin{array}{c}0.599 \\
(0.725)\end{array}$ & $\mathrm{I}(2)$ \\
\hline$C S \_P U B$ & $\begin{array}{c}0.440 \\
(0.670) \\
\end{array}$ & $\begin{array}{l}-1.214 \\
(0.112) \\
\end{array}$ & $\mathrm{I}(2)$ \\
\hline$P R I$ & $\begin{array}{c}0.341 \\
(0.633) \\
\end{array}$ & $\begin{array}{l}-2.859 \\
(0.002) \\
\end{array}$ & $\mathrm{I}(1)$ \\
\hline$P \cup B$ & $\begin{array}{l}-0.245 \\
(0.403) \\
\end{array}$ & $\begin{array}{l}-3.561 \\
(0.000) \\
\end{array}$ & $\mathrm{I}(1)$ \\
\hline$Y$ & $\begin{array}{c}0.205 \\
(0.581) \\
\end{array}$ & $\begin{array}{l}-2.264 \\
(0.012) \\
\end{array}$ & $\mathrm{I}(1)$ \\
\hline$R$ & $\begin{array}{c}1.203 \\
(0.886) \\
\end{array}$ & $\begin{array}{l}-3.105 \\
(0.001) \\
\end{array}$ & $\mathrm{I}(1)$ \\
\hline$D E B T$ & $\begin{array}{c}1.000 \\
(0.841)\end{array}$ & $\begin{array}{l}-3.418 \\
(0.000)\end{array}$ & $\mathrm{I}(1)$ \\
\hline
\end{tabular}

Tests for cointegration according to Westerlund (2007)

\begin{tabular}{|l|c|c|c|c|}
\hline & $\mathrm{G}_{\tau}$ & $\mathrm{G}_{\alpha}$ & $\mathrm{P}_{\tau}$ & $\mathrm{P}_{\alpha}$ \\
\hline CS_PRI, CS_PUB & $\begin{array}{c}-6.783 \\
(0.000)\end{array}$ & $\begin{array}{c}-9.608 \\
(0.000)\end{array}$ & $\begin{array}{c}-4.699 \\
(0.000)\end{array}$ & $\begin{array}{c}-1.771 \\
(0.038)\end{array}$ \\
\hline PRI, PUB & 2.973 & 2.983 & 3.172 & 1.698 \\
& $(0.904)$ & $(0.982)$ & $(0.920)$ & $(0.866)$ \\
\hline PRI, PUB, Y, R & -2.112 & -0.167 & -2.588 & -2.108 \\
& $(0.026)$ & $(0.022)$ & $(0.012)$ & $(0.004)$ \\
\hline PRI, PUB, Y, DEBT & -1.819 & 1.653 & -2.225 & -0.590 \\
& $(0.042)$ & $(0.456)$ & $(0.046)$ & $(0.142)$ \\
\hline
\end{tabular}

Note: 12 euro area countries (Germany, France, Italy, Spain, Portugal, Ireland, Austria, Finland, Netherlands, Belgium, Luxembourg and Greece, 1991-2012). Variables are private investment (PRI), public investment $(P U B)$, GDP $(Y)$, real interest rate $(R)$, government debt ratio $(D E B T)$. CS_PRIV and CS_PUB refer to the private and public capital stock, respectively. Selection of lags and deterministic terms are based on Akaike criterion. Entries are test statistics, $p$-values in parentheses. The $p$-values for the cointegration tests are based on bootstrap methods, where 500 replications are used. See Persyn and Westerlund (2008) for details. 
Table 2: Long run relationship in cointegrated models

\begin{tabular}{|l|c|c|c|}
\hline & $P R I$ & $P R I$ & CS_PRI \\
\hline$P U B$ & $0.208(0.033)$ & $0.236(0.038)$ & \\
\hline$Y$ & $0.879(0.055)$ & $1.116(0.058)$ & \\
\hline$R$ & $-0.029(0.003)$ & & \\
\hline$D E B T$ & & $-0.053(0.028)$ & \\
\hline CS_PUB & & & $0.785(0.024)$ \\
\hline$R$-SQUARED & 0.993 & 0.990 & 0.997 \\
\hline AIC & -1.544 & -1.275 & -2.202 \\
\hline
\end{tabular}

Note: 12 euro area countries (Germany, France, Italy, Spain, Portugal, Ireland, Austria, Finland, Netherlands, Belgium, Luxembourg and Greece, 1991-2012). Variables are gross private investment (PRI), gross public investment $(P U B), \operatorname{GDP}(Y)$, real interest rate $(R)$, government debt ratio $(D E B T)$. CS_PRI $\left(C S \_P U B\right)$ is the private (public) capital stock. Pooled regression with country fixed effects and cross section correlation in the residuals. Figures in parentheses denote standard errors. R-SQUARED is the adjusted coefficient of determination, AIC the Akaike information criterion. 
Table 3: Short and medium run responses to a one percent shock in investment

A Flow model

\begin{tabular}{|l|c|c|c|c|c|}
\hline & \multicolumn{3}{|c|}{ Impulse responses } & Variance decomposition \\
\hline PUB-Shock & 1 & 3 & 5 & 3 & 5 \\
\hline PUB & $0.111^{*}$ & $0.043^{*}$ & 0.034 & 0.759 & 0.511 \\
\hline$R$ & -0.034 & 0.032 & 0.048 & 0.004 & 0.004 \\
\hline$Y$ & 0.000 & 0.001 & 0.004 & 0.001 & 0.001 \\
\hline$P R I$ & 0.015 & 0.024 & 0.025 & 0.026 & 0.034 \\
\hline
\end{tabular}

\begin{tabular}{|l|c|c|c|c|c|}
\hline & \multicolumn{3}{|c|}{ Impulse responses } & Variance decomposition \\
\hline$P R I$ Shock & 1 & 3 & 5 & 3 & 5 \\
\hline$P R I$ & $0.078^{*}$ & $0.070^{*}$ & $0.066^{*}$ & 0.626 & 0.482 \\
\hline$R$ & -0.032 & -0.010 & 0.028 & 0.000 & 0.001 \\
\hline$Y$ & 0.008 & 0.018 & 0.022 & 0.058 & 0.128 \\
\hline PUB & $0.041^{*}$ & $0.065^{*}$ & $0.064^{*}$ & 0.197 & 0.304 \\
\hline
\end{tabular}

B Stock model

Shock in public investment

\begin{tabular}{|l|c|c|c|c|c|}
\hline & \multicolumn{3}{|c|}{ Impulse responses } & Variance decomposition \\
\hline CS_PUB shock & 1 & 3 & 5 & 3 & 5 \\
\hline CS_PUB & $0.014^{*}$ & $0.013^{*}$ & $0.012^{*}$ & 0.993 & 0.977 \\
\hline CS_PRI & $0.008^{*}$ & $0.007^{*}$ & $0.007^{*}$ & 0.447 & 0.507 \\
\hline
\end{tabular}

Shock in private investment 


\begin{tabular}{|l|c|c|c|c|c|}
\hline CS_PRI shock & 1 & 3 & 5 & 3 & 5 \\
\hline$C S \_P R I$ & $0.010^{*}$ & $0.007^{*}$ & $0.004^{*}$ & 0.553 & 0.493 \\
\hline$C S \_P U B$ & $-0.001^{*}$ & $-0.002^{*}$ & $-0.003^{*}$ & 0.007 & 0.023 \\
\hline
\end{tabular}

Note: 12 euro area countries (Germany, France, Italy, Spain, Portugal, Ireland, Austria, Finland, Netherlands, Belgium, Luxembourg and Greece, 1991-2012). Variables are gross private investment (PRI), gross public investment $(P U B), \operatorname{GDP}(Y)$, real interest rate $(R)$. CS_PRI (CS_PUB) is the private (public) capital stock. Entries denote impulse reponses 1, 3 and 5 years after the shock in public or private investment and the percentage of the forecast error variance that can be attributed to fluctuations in the shock variable after 3 and 5 years. An asterisk indicates significance at the 0.05 level, where standard errors are determined by Monte Carlo methods. 